\title{
Interlab: Interactive Technologies Laboratory
}

\author{
Romero Tori*, Ricardo Nakamura*, Fátima L. S. Nunes ${ }^{\dagger}$, \\ João L. Bernardes Jr. ${ }^{\dagger}$, Maria Alice G. V. Ferreira* and Edith Ranzini* \\ *Escola Politécnica, Universidade de São Paulo, Brasil \\ Email: \{romero.tori, ricardo.nakamura, maria.alice.ferreira, edith.ranzini\}@ poli.usp.br \\ †Escola de Artes, Ciências e Humanidades, Universidade de São Paulo, Brasil \\ Email: \{fatima.nunes, jlbernardes\}@usp.br
}

\begin{abstract}
The Interactive Technologies Laboratory (Interlab) is an applied research laboratory of the Escola Politécnica at Universidade de São Paulo (USP) aiming at developing research related to three-dimensional interaction in virtual environments. An overview of Interlab, including its origin, research lines and some of the ongoing projects are presented. Projects in Interlab are related to three research lines, which are Digital Games, Virtual and Augmented Reality and Interactive Technologies in Education. Often projects involve more than one line, following a multidisciplinary approach. Among the major works in progress can be highlighted: VIDA (Virtual Interactive Distance-learning on Anatomy), Video-avatar Project, ViMeT (Virtual Medical Training) framework, Gestures2Go (Gesture recognition for interaction in 3D environments), AE-3D (3D Virtual Environment for Learning) and Presence and Learning Evaluation in Virtual Environments. Interlab has produced significant contributions in research, teaching and extension, with the support of different knowledge areas, such as health, education and design.

Index Terms-interaction; virtual atlas; gesture recognition; learning; games.
\end{abstract}

\section{INTRODUCTION}

Interlab (Interactive Technologies Laboratory) is an applied research laboratory at the Computer and Digital Systems Engineering Department of the Escola Politécnica at Universidade de São Paulo (USP). The laboratory is focused on new interactive technologies, such as virtual reality, augmented reality and games, for the development of innovative solutions in areas such as Education, Medicine and Entertainment. Besides research projects, Interlab performs other activities on technology and knowledge diffusion, including didactic material, courses and seminars. Interlab was founded in 1996, by merging two former groups, GRV (Virtual Reality Group, created by Prof. Dr. Antonio Helio Guerra Vieira in 1992) and GCAD (CAD and Computer Graphics Group, created by Prof. Dr. Antonio Marcos de Aguirra Massola in 1985). Since 2002, Interlab also includes a group dedicated to research into digital game technology and interfaces and their application in fields such as education. Currently Interlab's team has 15 professors and around 25 students, including $\mathrm{PhD}$, Master and undergraduation levels.

With a multidisciplinary approach, research projects carried out at Interlab combine knowledge of computer engineering, design and the domains of the applications involved, aiming at producing innovation in unexplored niches lying at the interfaces between different areas of expertise. Hence, Interlab is collaborating with several research groups, such as Escola do Futuro at USP, LApIS - Health Informatics Applications Laboratory (EACH-USP), DEVIR - Design, Virtuality and Networks (FAU-USP), Studies of Deaf Communities (FFLCHUSP), LPAI - Research Lab in Interactive Environments (Centro Universitário Senac), INCT MACC (Medicine Aided by Scientific Computing) and Laboratory for Computer Graphics (Universidade Federal de Uberlândia).

Among the several projects developed at Interlab, the following can be mentioned: AVTC (Augmented Virtuality TeleConferencing; an architecture for immersive teleconference based on stereoscopic video avatar in virtual three-dimensional environment), VIDA (Virtual Interactive Distance-learning on Anatomy), VIMET (VIrtual MEdical Training; a framework for development of applications for medical training), Gestures2Go (gesture recognition for interaction in 3D environments), Enjine (didactic game engine in Java), Interlab3D (a tool for teaching scene graphs in Java 3D), AE-3D (3D Environment as an interface to virtual learning environments), Virtual Laboratory of Physics, 3D Virtual Museum, PIAGET (a distributed virtual reality environment applied to collaborative learning ontology and educational application platforms) and an Architecture for Modeling behavior of non-player characters in games based on the BDI (Belief-Desire-Intention) model.

\section{RESEARCH LINES}

Interlab projects are related to three research lines, which are described in this section. Some projects actually involve more than one line, following a multidisciplinary approach.

Digital Games: The research on digital games, which was initially motivated by the growth in complexity of projects in this area, includes different fields such as human-computer interaction, software engineering, computer graphics, behavior simulation, design, communication and psychology. Our focus in this line of research is on aspects related to digital game interactive technologies, such as user experience and interaction techniques. Also research in "serious games" has been recently investigated, mainly related to health and education subjects. Some recent articles produced under this research line: [1] [2] [3] [4] [5].

Virtual and Augmented Reality: New forms of threedimensional interaction based on the integration of real and virtual elements and environments are investigated in this 
line. It encompasses both the development of new technology hardware and software as well as interface design and innovative applications, especially in health, education and entertainment. A recent research topic in this line is the conception of methodologies to evaluate cognition and skills acquisition provided by virtual environments. Some recent articles produced under this reserach line: [6] [7] [8] [9] [10] [11] [12] [13].

Interactive Technologies in Education: New boundaries of educational technology are explored along this line, with the use of interactive technologies to reduce distance and increase the sensation of presence. New technologies and interfaces have been developed, as well as tools and applications, learning activities, methodologies and materials, including the evaluation of this technology and its influence on learning. Some recent articles produced under this reserach line: [14] [15] [16] [9] [11] [13] [17].

\section{Current Projects}

This section presents an overview of some research projects under development in Interlab.

\section{A. VIDA - Virtual Interactive Distance-learning on Anatomy}

This project consists of a solution for low-cost distancelearning on anatomy, involving direct manipulation and visualization of anatomical structures, in real-time. This approach aims to increase the realism and sensation of presence, thus providing more involvement and motivation for students. Figure 1 presents a concept image of the system. This project is conducted in a collaborative effort between Interlab/POLI USP, Lapis/EACH USP and LPAI/Senac. [8] [9] [11].

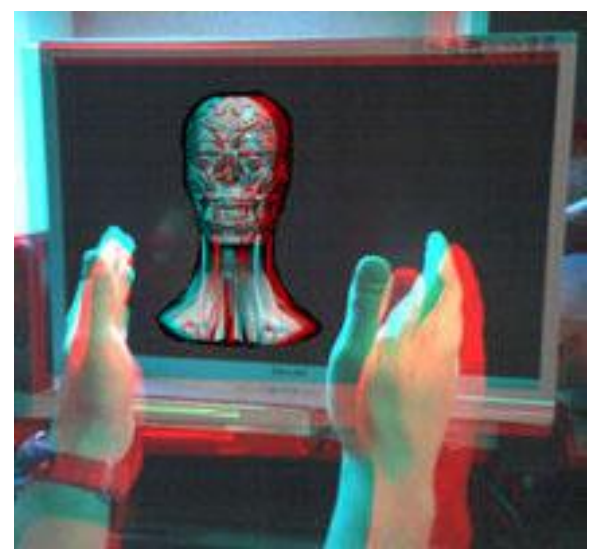

Fig. 1. Concept image of interaction in VIDA Environment (in anaglyph format)

\section{B. Video Avatar Immersive Telecommunication}

The Video-avatar Project [10] [12] [13] comprises several research efforts in developing innovative solutions for an immersive videoconferencing system, which allows presenters to immerse themselves in a $3 \mathrm{D}$ virtual environment, through their video-avatar, and be watched remotely in the form of
3D video, as illustrated in Figure 2. This system integrates subprojects involving the capture and rendering of a videoavatar, background removal, gesture recognition, interaction design, among others.

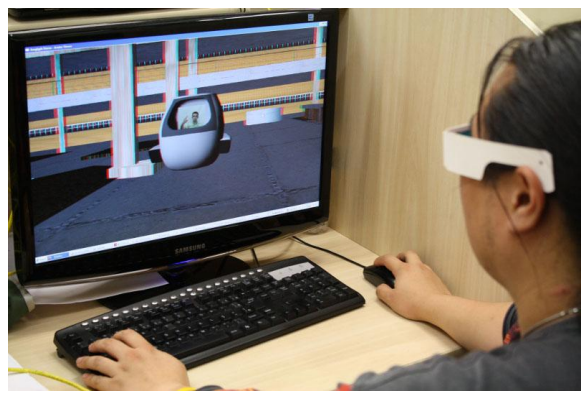

Fig. 2. User interacting with a video-avatar of a remote presenter

\section{ViMeT - Virtual Medical Training}

ViMeT is a Virtual Reality Framework composed of classes using object-orientation to generate applications to simulate biopsy exams [18]. It is directed to programmers who can directly instantiate their classes or generate an application by using a wizard tool [19]. The resultant application (example in Figure 3) is codified in Java language and provides functionalities such as collision detection, deformation, navigation, stereoscopy and interaction with conventional and nonconventional devices. The ViMeT Framework is developed in a collaboration with LApIS (Health Informatics Applications Laboratory ) and it is available at http://www.each.usp.br/ lapis/.

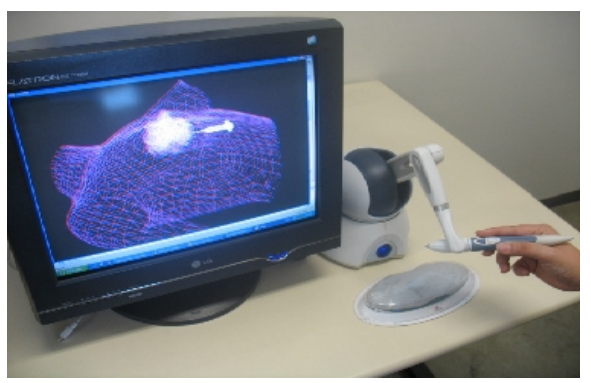

Fig. 3. User interacting with a video-avatar of a remote presenter

\section{Gestures2Go - Free Hand Gesture Model and Recognition for $3 D$ Environments}

Gestures2go [3] allows the recognition of free hand gestures to be used in interaction in 3D environments, especially for entertainment and education applications, using low cost equipment. The gestures may be selected from a large set of possibilities and associated to interface actions in execution time, with different gestures and associations for different interaction contexts. The large set of possible gestures increases the probability of selecting gestures that are pertinent 
to the application domain or that have a clear logic association with the actions they command, thus facilitating the learning, memorization and use of the gestural interface. Figure 4 shows a commercial digital game being controlled by Gestures2Go, with a feedback window in the lower left corner showing users how their hands and head are detected.

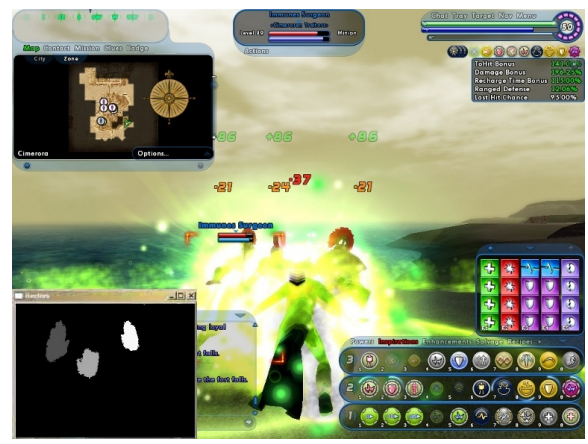

Fig. 4. Entertainment application controlled by Gestures2Go

\section{E. AE-3D - 3D Virtual Environment for Learning}

AE is a Learning Management System Platform, supported by FAPESP, developed in a collaborative effort by several research institutions of the State of São Paulo. AE-3D [6] [16] is a research project aimed to create a 3D learning environment based on massive multiuser systems such as Second Life and Open Simulator. Therefore, it acts as a 3D interface that maps content and communications tools from AE to a 3D Virtual World, as illustrated in Figure 5. AE-3D is based on the premise that tutors and content managers do not have to be aware of the $3 \mathrm{D}$ alternative interface.

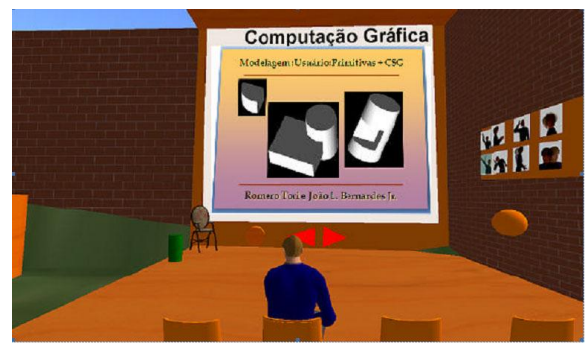

Fig. 5. AE-3D classroom

\section{F. Presence and Learning Evaluation in Virtual Environments}

In this research project, the aim is to develop methodologies in order to evaluate subjective perception of presence felt by users when he/she is interacting in a three-dimensional virtual environment. Currently, works are being conducted to define metrics to evaluate how much a user feels to be inside the virtual environment; how a user can acquire knowledge and/or abilities by using virtual environments. This project is developed in a collaboration with LApIS (Health Informatics Applications Laboratory).

\section{CONCLUSION}

Interlab (Interactive Technologies Laboratory), laboratory linked to Escola Politécnica / the School of Engineering at the Universidade de São Paulo / University of São Paulo (USP) is presented, which counts on a 15-year experience in the study and development of innovative solutions on the use of technologies that provide users with a high degree of interactivity and the feeling of presence. Interlab has produced significant contributions in research, teaching and extension, involving themes going from Interactive Computer Graphics to Augmented Reality, going through digital games, with the support of different knowledge areas, such as health, education and design. Students and collaborators interested in research considering the mentioned areas are welcome. Further information on the laboratory, its members and their production can be found at http://interlab.pcs.poli.usp.br.

\section{REFERENCES}

[1] J. L. Bernardes Jr., R. Nakamura, D. Calife, D. Tokunaga, and R. Tori, "Integrating the wii controller with enjine," Computers in Entertainment, vol. 7, 2009.

[2] R. Nakamura, L. L. M. Lago, A. B. Carneiro, A. J. C. Cunha, F. J. M. Ortega, J. L. Bernardes Jr., and R. Tori, "3pi experiment: immersion in third-person view," in Proceedings of the 5th ACM SIGGRAPH Symposium on Video Games, 2010.

[3] J. L. Bernardes Jr., R. Nakamura, and R. Tori, "Design and implementation of a flexible hand gesture command interface for games based on computer vision," in Proceedings of SBGAMES 2009 - VIII Brazilian Symposium on Games and Digital Entertainment, 2009, pp. 89-98.

[4] A. Tomoyose, S. R. R. Sanches, and R. Tori, "Integração da estereoscopia à mecânica dos jogos," in Proceedings of SBGAMES 2009 - VIII Brazilian Symposium on Games and Digital Entertainment, 2009, pp. $1-8$.

[5] R. Nakamura and R. Tori, "Processing como ferramenta para game design," in Proceedings of SBGAMES 2009 - VIII Brazilian Symposium on Games and Digital Entertainment, 2009, pp. 1-22.

[6] S. R. R. Sanches, A. C. Silva, and R. Tori, "Uma experiência de educação a distância realizada em ambiente virtual tridimensional," Revista Brasileira de Computação Aplicada, vol. 2, pp. 47-57, 2010.

[7] R. Tori, "Desafios para o design de informação em ambientes de realidade aumentada," Infodesign, vol. 6, pp. 1-12, 2009.

[8] R. Tori, D. M. Tokunaga, R. Nakamura, F. L. S. N. Marques, C. G. Correa, and F. Picchi, "Visualização não-fotorrealística no design de interação do ambiente vida," in Anais do $P$ \& D Design - Congresso brasileiro de pesquisa e desenvolvimento em design, 2010.

[9] R. Tori, F. L. S. N. Marques, R. Nakamura, J. L. Bernardes Jr., C. G. Correa, and D. M. Tokunaga, "Design de interação para um atlas virtual de anatomia usando realidade aumentada e gestos," in Proceedings of Interaction South America 09, 2009, pp. 1-12.

[10] S. R. R. Sanches, A. C. Sementille, and R. Tori, "Método para segmentação de vídeo em tempo-real para aplicações em teleimersão," in Proceedings of XI Symposium on Virtual and Augmented Reality, 2009, pp. 175-184.

[11] R. Tori, F. L. S. N. Marques, V. H. P. Gomes, and D. M. Tokunaga, "Vida: Atlas anatômico 3d interativo para treinamento a distância," in Anais do XXIX Congresso da Sociedade Brasileira de Computação, 2009, pp. 1-10.

[12] D. M. Tokunaga, S. R. R. Sanches, L. P. Trias, J. L. Bernardes Jr., R. Nakamura, and R. Tori, "Video-based microfacet-billboard avatar for educational immersive teleconference systems," in Proceedings of XI Symposium on Virtual and Augmented Reality, 2009, pp. 199-209.

[13] C. G. Correa, D. M. Tokunaga, S. R. R. Sanches, R. Nakamura, and R. Tori, "Immersive teleconferencing system based on video-avatar for distance learning," in Proceedings of XIII Symposium on Virtual and Augmented Reality, 2011, pp. 197-206.

[14] R. Tori, Educação sem distância: As Tecnologias Interativas na Redução de Distâncias em Ensino e Aprendizagem, 1st ed. Editora Senac, 2010. 
[15] —_, "A presença das tecnologias interativas na educação," Revista de Computação e Tecnologia da PUC-SP, vol. 2, pp. 1-13, 2010.

[16] V. F. Silva, S. R. R. Sanches, A. C. Silva, A. Zotovici, and R. Tori, "Camada de interoperabilidade entre o ambiente de aprendizagem tidiaae e ambientes virtuais tridimensionais," in Anais do WIE 2009 - XV Workshop Sobre Informática na Escola, 2009, pp. 1-10.

[17] S. G. Puga and M. A. G. V. Ferreira, "Sistemas hipermídia adaptativos pra a ebw - uma visão semiótica," Cadernos de Pesquisa Revista Cientifica, vol. 1, no. 1, pp. 3-28, 2009.

[18] A. C. M. T. G. Oliveira and F. L. S. Nunes, "Building an open source framework for virtual medical training," Journal of Digital Imaging, vol. 23 , no. 6, pp. 706-720, 2010.

[19] F. L. S. Nunes, A. C. M. T. G. Oliveira, D. J. Rossato, and M. I. C. Machado, "Vimetwizard: Uma ferramenta para instanciação de um framework de realidade virtual para treinamento médico," in Proceedings of XXXIII Conferencia Latinoamericana de Informática, 2007, pp. $1-8$. 